\title{
Direct Electron Transfer of Cytochrome c on ZnO Nanoparticles Modified Carbon Paste Electrode
}

\author{
Masoud Negahdary, ${ }^{1}$ Saeed Rezaei-Zarchi, ${ }^{2}$ Neda Rousta, ${ }^{1}$ and Soheila Samei Pour ${ }^{1}$ \\ ${ }^{1}$ Department of Biochemistry, Payam-e-Noor University, 7371719578 Tehran, Iran \\ ${ }^{2}$ Department of Biology, Payam-e-Noor University, Yazd, Iran
}

Correspondence should be addressed to Masoud Negahdary, masoud_negahdary@yahoo.com

Received 3 January 2012; Accepted 19 January 2012

Academic Editors: D. Bulone and M. P. Ponomarenko

Copyright (C) 2012 Masoud Negahdary et al. This is an open access article distributed under the Creative Commons Attribution License, which permits unrestricted use, distribution, and reproduction in any medium, provided the original work is properly cited.

The direct electrochemistry of cytochrome c (cyt c) immobilized on a modified carbon paste electrode (CPE) was described. The electrode was modified with $\mathrm{ZnO}$ nanoparticles. Direct electrochemistry of cytochrome $\mathrm{c}$ in this paste electrode was easily achieved, and a pair of well-defined quasireversible redox peaks of a heme Fe (III)/Fe(II) couple appeared with a formal potential $\left(E^{0}\right)$ of $-0.303 \mathrm{~V}$ (versus SCE) in $\mathrm{pH} 7.0$ phosphate buffer solution (PBS). The fabricated modified bioelectrode showed good electrocatalytic ability for reduction of $\mathrm{H}_{2} \mathrm{O}_{2}$. The preparation process of the proposed biosensor was convenient, and the resulting biosensor showed high sensitivity, low detection limit, and good stability.

\section{Introduction}

Many fields of nanotechnology are based on physical and chemical interactions, involving nanoparticles of particular size and shape. Nanoparticles (NPs) played an important role in absorption/adsorption of (volatile) organic molecules and gases due to their large specific surface area and high surface energy [1]. Nanoscaled inorganic materials have received much more attention because of their high chemical inertness, nonswelling effect, high purity, and rigidity [2, $3]$. In order to use the nanomaterials as sensors, one has to understand the peculiarities of both the synthesis and interaction mechanism during the sensing act. In recent years, the interest of researchers and engineers in gas and liquid-sensitive materials has grown substantially due to the progress in nanotechnology [4]. This interest is primarily connected to the promising electronic properties of nanomaterials, their size dependence, and the possibility of controlling the material structure by using new experimental techniques. Electrochemical sensors provide unlimited opportunities for monitoring environments and making the world safer and cleaner $[5,6]$. Such devices meet the environmental and security demands for monitoring electroactive pollutants or threat agents with high sensitivity, selectivity, and temporal resolution $[7,8]$. Electrochemical detection is of particular significance in the development of aptasensors since it allows for high sensitivity and selectivity, simple instrumentation, as well as low endogenetic background [6]. Zinc oxide $(\mathrm{ZnO})$, a versatile semiconductor material, has been attracting attention because of the commercial demand for optoelectronic devices operating at blue and ultraviolet regions [4]. $\mathrm{ZnO}$ is a wurtzite-type semiconductor with band gap energy of $3.37 \mathrm{eV}$, and it has very large excitation binding energy $(60 \mathrm{meV})$ at room temperature [9]. Recently, special attention has been devoted to the morphology, as $\mathrm{ZnO}$ can form different nanostructures [10]. Thermal stability, irradiation resistance, and flexibility to form different nanostructures are the advantages that expedite its potential wide applications in photodetectors [11-13], surface acoustic wave devices [14], ultraviolet nanolaser [15], varistors [16], solar cells [17], gas sensors [18], biosensors [19], ceramics $[20,21]$, field emission [22], and nanogenerator [23]. Cyt c plays an important role in the biological respiratory chain, whose function is to receive electrons from Cyt $\mathrm{c}$ reductase and deliver them to Cyt $\mathrm{c}$ oxidase. So the electrochemical study of Cyt c is very important [24]. Due to the difficulty of direct electron transfer between Cyt $\mathrm{c}$ and a bare electrode, some modified electrodes were used as a tool to investigate 
the direct electrochemical property. The modifiers of these modified electrodes are organic [25] or inorganic [24, 25] compounds. They were found to promote the direct electron transfer of Cyt $\mathrm{c}$ at electrode surfaces. It is well accepted that Cyt $c$ exhibits peroxidase activities, which can catalyze the reductive reaction of hydrogen peroxide. Determinations to $\mathrm{H}_{2} \mathrm{O}_{2}$ based on such catalytic interactions are widely reported [26]. Effective immobilization and maintenance to the bioactivity on a proper substrate are essential to get a stable and sensitive response signal. Many methods for protein immobilization are extensively investigated, such as physical and biophysical methods $[27,28]$.

\section{Experimental}

2.1. Materials. Cytochrome c was purchased from Sigma. The phosphate buffer solution (PBS) consisted of a potassium phosphate solution $\left(\mathrm{KH}_{2} \mathrm{PO}_{4}\right.$ and $\mathrm{K}_{2} \mathrm{HPO}_{4}$ from Merck; $0.1 \mathrm{M}$ total phosphate) at $\mathrm{pH}$ 7.0. All other chemicals were of analytical grade and were used without further purification. All solutions were made up with doubly distilled water.

2.2. Apparatus. Cyclic voltammetric experiments were performed with a model EA-201 Electro Analyzer (chemilink systems), equipped with a personal computer that was used for electrochemical measurement and treating of data. A conventional three-electrode cell was employed throughout the experiments, with bare or $\mathrm{ZnO}$ nanoparticles modified carbon paste electrode $(4.0 \mathrm{~mm}$ diameter $)$ as a working electrode, a saturated calomel electrode (SCE) as a reference electrode, and a platinum electrode as a counter electrode. The phase characterization was performed by means of Xray diffraction (XRD) using a D/Max-RA diffractometer with $\mathrm{CuK} \alpha$ radiation. Samples were measured and recorded using a TU-1901 double-beam UV-visible spectrophotometer and were dispersed in toluene solution. The morphologies and particle sizes of the samples were characterized by JEM200CX transmission electron microscopy (TEM) working at $200 \mathrm{kV}$, and scanning electron microscopy (SEM) images were obtained with a ZIESS EM 902A scanning electron microscope.

\subsection{Procedure}

2.3.1. Synthesis of $Z n O N P$ s. To prepare of $\mathrm{ZnO} N P s$, in a typical experiment, a $0.45 \mathrm{M}$ aqueous solution of zinc nitrate $\left(\mathrm{Zn}\left(\mathrm{NO}_{3}\right)_{2} \cdot 4 \mathrm{H}_{2} \mathrm{O}\right)$ and $0.9 \mathrm{M}$ aqueous solution of sodium hydroxide $(\mathrm{NaOH})$ were prepared in distilled water. Then, the beaker containing $\mathrm{NaOH}$ solution was heated at the temperature of about $55^{\circ} \mathrm{C}$. The $\mathrm{Zn}\left(\mathrm{NO}_{3}\right)_{2}$ solution was added dropwise (slowly for $1 \mathrm{~h}$ ) to the above-heated solution under high-speed stirring. The beaker was sealed at this condition for $2 \mathrm{~h}$. The precipitated $\mathrm{ZnO}$ NPs were cleaned with deionized water and ethanol then dried in air atmosphere at about $60^{\circ} \mathrm{C}$.
2.3.2. Preparation of Carbon Paste Electrode. The carbon powder (particle size $50 \mathrm{~mm}$, density $20-30 \mathrm{~g} / 100 \mathrm{~mL}$ ) was mixed with the binder, silicone oil, in an agate mortar and homogenized using the pestle. The electrode consisted of a Teflon well, mounted at the end of a Teflon tube. The prepared paste was filled into the Teflon well. A copper wire fixed to a graphite rod and inserted into the Teflon tube served to establish electrical contact with the external circuit. The electrode surface of the working electrode was renewed mechanically by smoothing some paste off and then polishing on a piece of transparent paper before conducting each of the experiments. The experiments were performed in unstirred solutions.

2.3.3. Preparation of $\mathrm{ZnO}$ Nanoparticles Modified Carbon Paste Electrode. The ZnO-nanoparticle-modified carbon paste electrode was prepared by hand mixing of carbon powder, binder and $10 \mathrm{mg} \mathrm{ZnO}$ nanoparticle with silicon oil in an agate mortar to produce a homogenous carbon paste. Other steps of produced modified carbon paste electrode were similar to preparation of bare carbon paste electrode. A conventional three-electrode cell was employed throughout the experiments, with bare or $\mathrm{ZnO}$-nanoparticle-modified carbon paste electrode $(4.0 \mathrm{~mm}$ diameter) as a working electrode, a saturated calomel electrode (SCE) as a reference electrode, and a platinum electrode as a counter electrode.

\section{Results}

3.1. Electron Microscopic Investigation of $\mathrm{ZnO}$ Nanoparticles. Morphology of the sample was investigated using SEM and TEM. Figures 1(a) and 1(b) of Figure 1 show the typical SEM and TEM images of the sample, respectively. The SEM image was captured in 500-nanometer size of $\mathrm{ZnO}$ nanoparticles, and the TEM image was captured in 90 nanometer size of $\mathrm{ZnO}$ nanoparticles.

3.2. X-Ray Diffraction of $\mathrm{ZnO}$ Nanoparticles. The X-ray diffraction data were recorded by using $\mathrm{Cu} K \alpha$ radiation $\left(1.5406 \mathrm{~A}^{\circ}\right)$. The intensity data were collected over a $2 \theta$ range of $20-80^{\circ}$. The average grain size of the samples was estimated with the help of Scherrer equation using the diffraction intensity of (101) peak. X-ray diffraction studies confirmed that the synthesized materials were $\mathrm{ZnO}$ with wurtzite phase, and all the diffraction peaks agreed with the reported JCPDS data, and no characteristic peaks were observed other than $\mathrm{ZnO}$. The mean grain size $(D)$ of the particles was determined from the XRD line broadening measurement using Scherrer equation [29]:

$$
D=\frac{0.89 \lambda}{\beta \operatorname{Cos} \theta},
$$

where $\lambda$ is the wavelength $(\mathrm{Cu} \mathrm{K} \alpha), \beta$ is the full width at the half-maximum (FWHM) of the $\mathrm{ZnO}$ (101) line, and $\theta$ is the diffraction angle. A definite line broadening of the diffraction peaks is an indication that the synthesized materials are in nanometer range. The lattice parameters calculated were also in agreement with the reported values. The reaction 


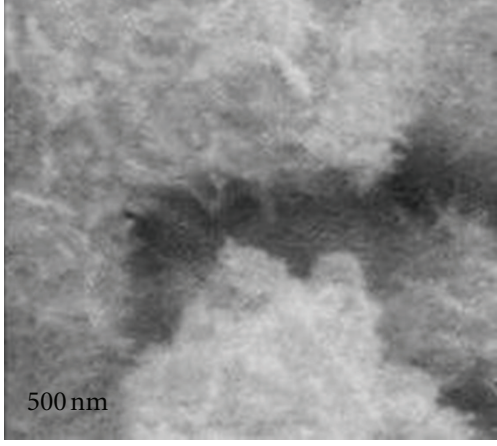

(a)

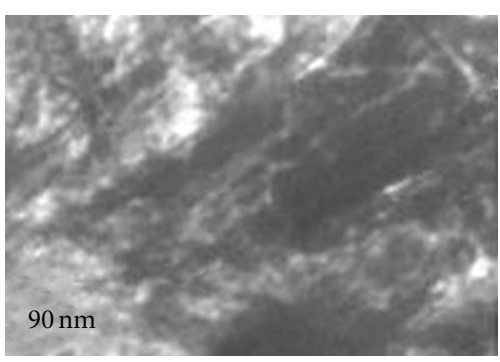

(b)

Figure 1: (a) SEM image and (b) TEM image of ZnO NPs.

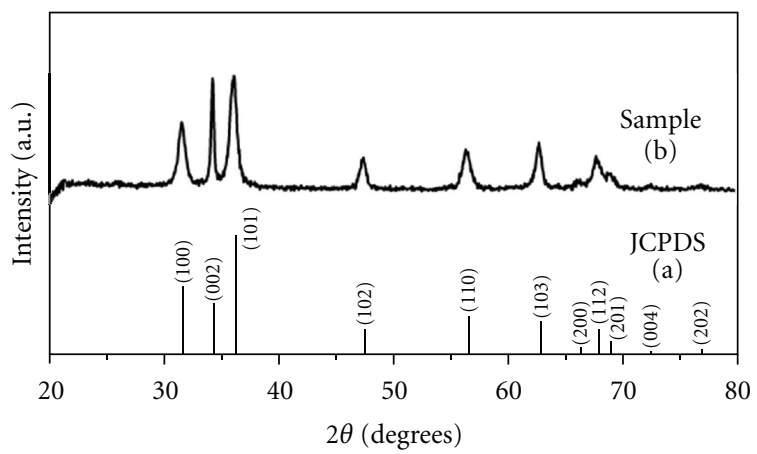

FIgURE 2: XRD patterns of $\mathrm{ZnO}$ nanoparticles. (a) indicates standard XRD pattern, and (b) indicates sample XRD pattern.

temperature greatly influences the particle morphology of asprepared $\mathrm{ZnO}$ powders. Figures 2(a) and 2(b) show the XRD patterns of $\mathrm{ZnO}$ nanoparticles.

3.3. UV-Visible Absorption Spectra for ZnO Nanoparticles. The UV-visible absorption spectra of $\mathrm{ZnO}$ nanoparticles are shown in Figure 3; although the wavelength of our spectrometer is limited by the light source, the absorption band of the $\mathrm{ZnO}$ nanoparticles shows a blue shift due to the quantum confinement of the excitons present in the sample compared with bulk $\mathrm{ZnO}$ particles. This optical phenomenon indicates that these nanoparticles show the quantum size effect [30].

\subsection{Direct Voltammetric Behavior of the Cyt c/ZnO NPs/CPE} Electrode. The integrity of the immobilized cytochrome $\mathrm{c}$ construction and its ability to exchange electrons with the

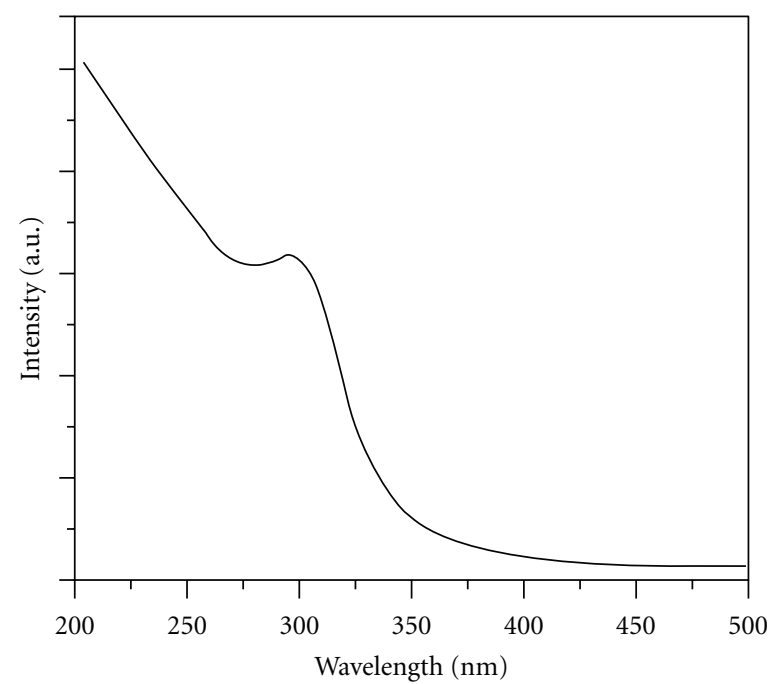

FIgURE 3: UV-Vis absorption spectra for $\mathrm{ZnO}$ nanoparticles.

nanometer-scale $\mathrm{ZnO}$ particles surfaces were assessed by voltammetry. A macroscopic electrode was required to attain a large enough cytochrome c sample to yield detectable direct oxidation and reduction currents. The comparative CVs for the $\mathrm{ZnO} \mathrm{NPs} / \mathrm{CPE}$ and $\mathrm{Cyt} \mathrm{c} / \mathrm{Zn}$ NPs/CPE electrodes in $0.1 \mathrm{M}$ PBS ( $\mathrm{pH} 7.0$ ) were obtained. These voltammograms are demonstrated in Figures 4(a) and 4(b). From this figure, it was noticed that there was no voltammetric response on $\mathrm{ZnO}$ NPs/carbon paste electrode (Figure 4(a)) Figure 4(b) depicts a well-defined pair of oxidation-reduction (redox) peaks, observed on the Cyt c/Zn NPs carbon paste electrode at $100 \mathrm{mV} / \mathrm{s}$ scan rate value. The Cyt c/Zn NPs/carbon paste electrode presented the reductive peak potential at $-0.325 \mathrm{~V}$ and the corresponding oxidative peak potential at $-0.280 \mathrm{~V}$ (at $100 \mathrm{mV} \mathrm{s}^{-1}$ ), illustrating the adsorbed cytochrome c on the nanometer-scale zinc oxide particle surfaces. The difference of anodic and cathodic peak potential values was $\Delta E=0.045 \mathrm{~V}$. These redox peaks were attributed to the redox reaction of the cytochrome $c$ electroactive center. The formal potential $\left(E^{0}\right)$ for the cytochrome c redox reaction on the Cyt $\mathrm{c} / \mathrm{Zn}$ NPs/carbon paste electrode was $-0.303 \mathrm{~V}$ with respect to the reference electrode.

The collected voltammograms in Figure 5(a) substantiated this statement that the nanometer-scale nickel oxide particles could play a key role in the observation of the cytochrome c CV response. On the grounds that the surface-to-volume ratio increases with the size decrease and because of the fact that the protein size is comparable with the nanometer-scale building blocks, these nanoparticles displayed a great effect on the electron exchange assistance between cytochrome $\mathrm{c}$ and carbon paste electrode. To further investigate the cytochrome $\mathrm{c}$ characteristics at the Cyt $\mathrm{c} / \mathrm{ZnO}$ NPs/CPE electrode, the effect of scan rates on the cytochrome c voltammetric behavior was studied in detail. The baseline subtraction procedure for the cyclic voltammograms was obtained in accordance with the method reported by Bard and Faulkner [31]. The scan rate $(\nu)$ and the square root scan rate $\left(\nu^{1 / 2}\right)$ dependence of the heights and potentials of 


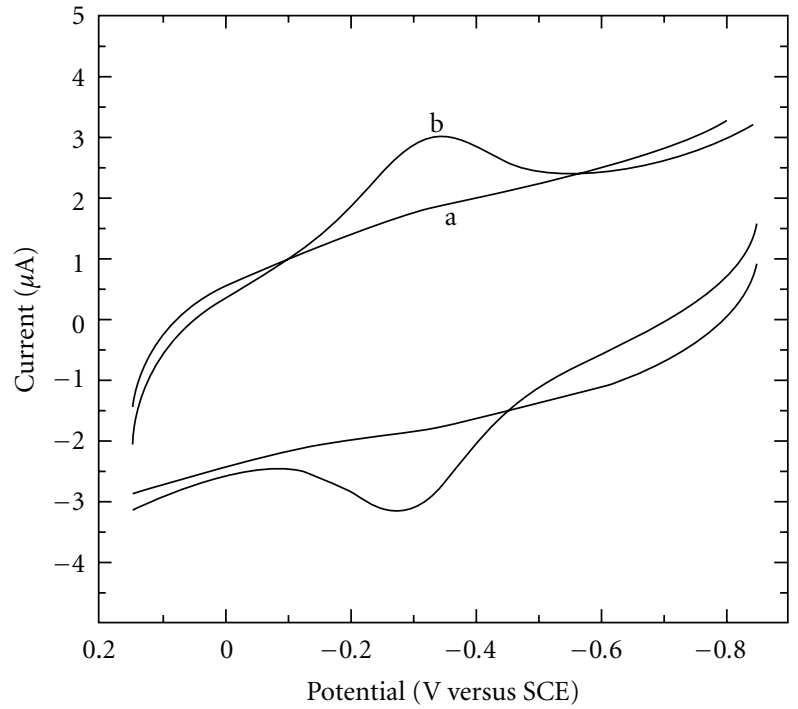

Figure 4: Cyclic voltammograms, using (a) the ZnO NPs/CPE in $0.1 \mathrm{M}$ phosphate buffer and (b) Cyt c/Zn NPs/CPE in $0.1 \mathrm{M}$ phosphate buffer (scan rate: $100 \mathrm{mV} / \mathrm{s}$ ).

the peaks are plotted in Figures 5(b) and 5(c). It can be seen that the redox peak currents increased linearly with the scan rate, the correlation coefficient was 0.9948 (ipc $=0.0119 v+$ 1.7389 ) and 0.9937 (ipa $=-.0168 v-1.6163)$, respectively. This phenomenon suggested that the redox process was an adsorption controlled and the immobilized cytochrome $c$ was stable. It can be seen that the redox peak currents increased more linearly with the $v$ in comparison to that of $v^{1 / 2}$.

However, there is clearly a systematic deviation from linearity in this data, that is, low scan rates are always on one side of the line and the high scan rate points are on the other. The anodic and cathodic peak potentials are linearly dependent on the logarithm of the scan rates $(\nu)$ when $v>1.0 \mathrm{~V} \mathrm{~s}^{-1}$, which was in agreement with the Laviron theory, with slopes of $-2.3 R T / \alpha n F$ and $2.3 R T /(1-$ $\alpha) n F$ for the cathodic and the anodic peak, respectively [32]. So the charge-transfer coefficient $(\alpha)$ was estimated as 0.55 . Furthermore, the heterogeneous electron transfer rate constant $(k s)$ was estimated according to the following equation $[32,33]$ :

$$
\begin{gathered}
{[\log k s=\alpha \log (1-\alpha)+(1-\alpha) \log \alpha} \\
\left.-\log \frac{R T}{n F v}-\frac{\alpha(1-\alpha) n F \Delta E_{P}}{2.3 R T}\right] .
\end{gathered}
$$

Here, $n$ is the number of transferred electrons at the rate of determining reaction and $R, T$, and $F$ symbols having their conventional meanings. $\Delta E_{p}$ is the peak potential separation. The $\Delta E_{p}$ was equal to $0.330,0.450$, and $0.512 \mathrm{~V}$ at $0.7,1$ and $2 \mathrm{~V} \mathrm{~s}^{-1}$, respectively, giving an average heterogeneous transfer rate constant $(k s)$ value of $0.64 \mathrm{~s}^{-1}$.

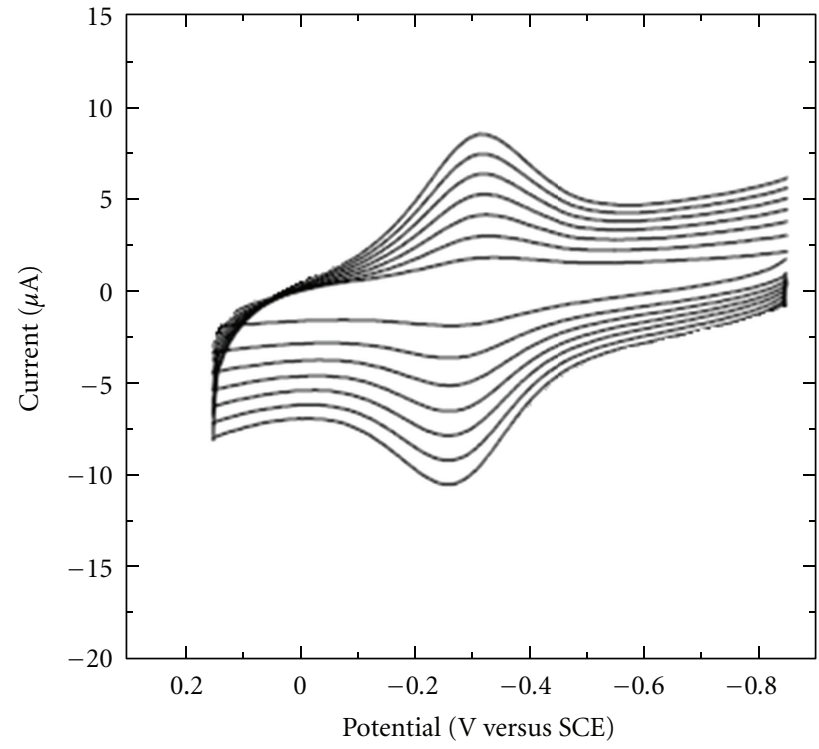

(a)

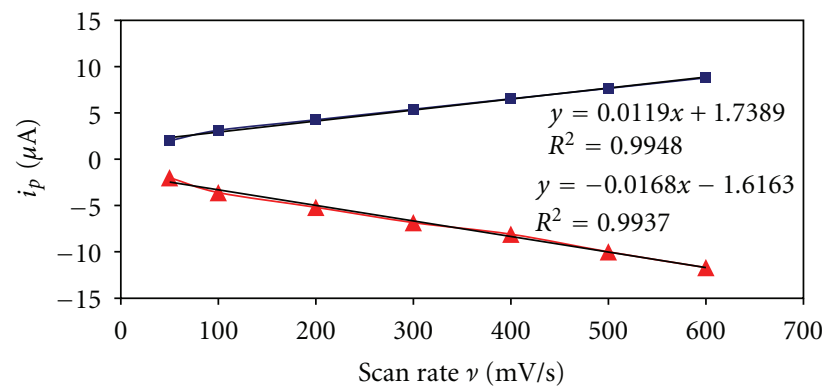

(b)

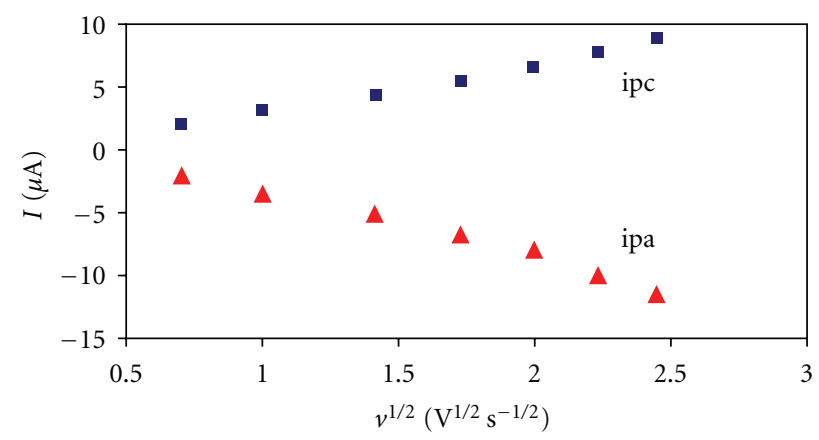

(c)

Figure 5: (a) CVs of Cyt c/ZnO NPs/CPE electrode in PBS at various scan rates, from inner to outer; 50, 100, 200, 300,400, 500, and $600 \mathrm{mV} \mathrm{s}^{-1}$, the relationship between the peak currents (ipa, ipc) versus (b) the sweep rates and (c) the square root of sweep rates.

3.5. Electrocatalytic Reduction of $\mathrm{H}_{2} \mathrm{O}_{2}$ on the Cyt $c / \mathrm{ZnO}$ $N P s / C P E-R e t a i n e d$ Electrode. Upon addition of $\mathrm{H}_{2} \mathrm{O}_{2}$ to $0.1 \mathrm{M}$ pH 7.0 PBS, the cyclic voltammogram of the Cyt $\mathrm{c} / \mathrm{ZnO} \mathrm{NPs} / \mathrm{CPE}$ electrode for the direct electron transfer of cyt c changed dramatically with an increase of reduction peak current and a decrease of oxidation peak current (Figure 6(a)), while the change of cyclic voltammogram of bare or $\mathrm{ZnO} \mathrm{Nps} / \mathrm{CPE}$ was negligible (not shown), displaying an 


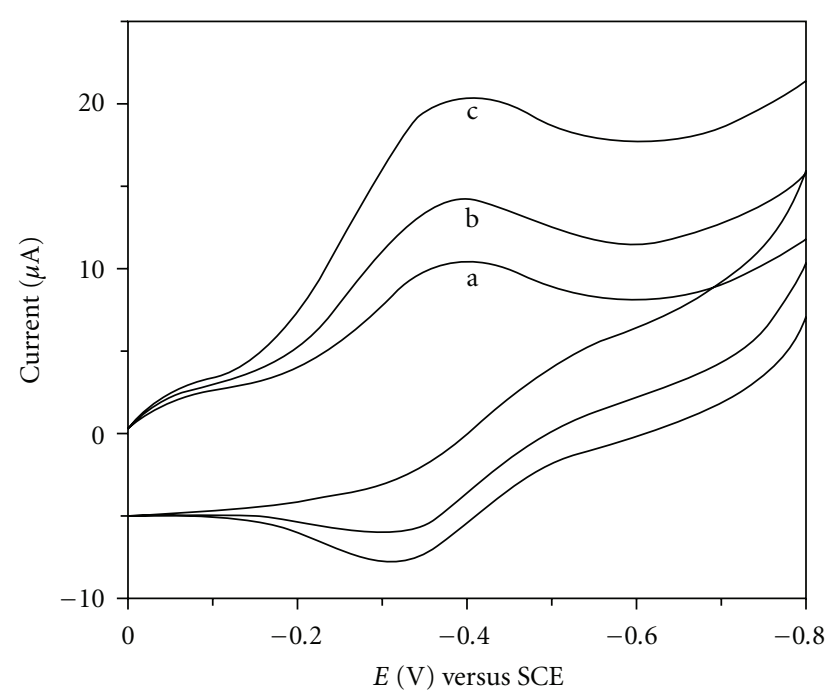

(a)

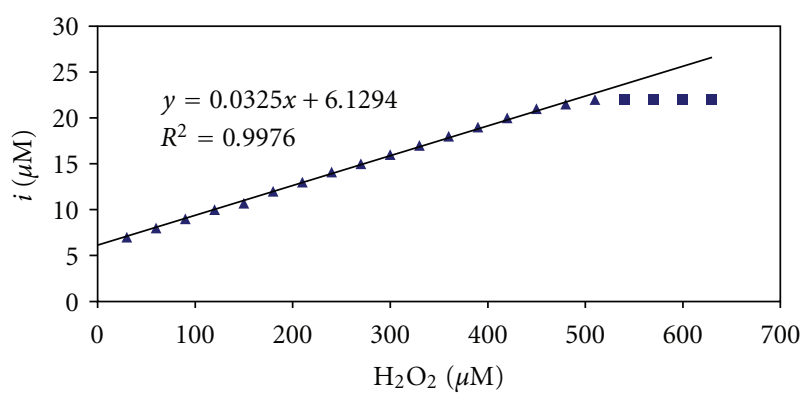

(b)

Figure 6: (a) Cyclic voltammograms obtained at an Cyt c/ZnO $\mathrm{NPs} / \mathrm{CPE}$ in $0.1 \mathrm{M}$ phosphate buffer solution ( $\mathrm{pH}$ 7.0) for different concentrations and (b) the relationship between cathodic peak current of cyt $\mathrm{c}$ and different concentrations of $\mathrm{H}_{2} \mathrm{O}_{2}$ (scan rate: $\left.100 \mathrm{mVs}^{-1}\right)$.

obvious electrocatalytic behavior of the cyt $\mathrm{c}$ to the reduction of $\mathrm{H}_{2} \mathrm{O}_{2}$. The decreases of the oxidative peak current together with the increases of the reductive Cyt c/ZnO NPs/CPE. The electrocatalytic process could be expressed as follows:

$$
\begin{aligned}
& \text { Cyt c Fe(III) }+\mathrm{H}_{2} \mathrm{O}_{2} \longrightarrow \text { Compound } \mathrm{I}+\mathrm{H}_{2} \mathrm{O} \\
& \text { Compound I }+\mathrm{H}_{2} \mathrm{O}_{2} \longrightarrow \text { cyt c Fe(III) }+\mathrm{O}_{2}+\mathrm{H}_{2} \mathrm{O} \\
& \text { Cyt c Fe (III) }+\mathrm{H}^{+}+\mathrm{e}^{-} \longrightarrow \text { cyt c Fe(II) (at electrode) } \\
& \text { Cyt c Fe(II) }+\mathrm{O}_{2} \longrightarrow \text { cyt c Fe(II) }-\mathrm{O}_{2} \text { (fast) } \\
& \text { Cyt c Fe(II) }-\mathrm{O}_{2}+2 \mathrm{H}^{+}+2 \mathrm{e}^{-} \\
& \quad \longrightarrow \text { Cyt c Fe(II) }+\mathrm{H}_{2} \mathrm{O}_{2} \text { (at electrode) }
\end{aligned}
$$

Calibration curve (Figure 6(b)) shows the linear dependence of the cathodic peak current on the $\mathrm{H}_{2} \mathrm{O}_{2}$ concentration in the range of 30 to $510 \mu \mathrm{M}$. In Figure 6(b), at higher concentration of $\mathrm{H}_{2} \mathrm{O}_{2}$, the cathodic peak current decreased and remained constant. Upon addition of an aliquot of $\mathrm{H}_{2} \mathrm{O}_{2}$ to the buffer solution, the reduction current increased steeply to reach a stable value (Figure 6(b). This implies electrocatalytic property of electrode. Thus, this experiment has introduced a new biosensor for the sensitive determination of $\mathrm{H}_{2} \mathrm{O}_{2}$ in solution.

\section{Conclusions}

Zinc oxide nanoparticles ( $\mathrm{ZnO} \mathrm{NPs}$ ) were electrodeposited onto the surface of carbon paste electrode and assessed using SEM and TEM procedures. The direct electrochemistry of cytochrome $\mathrm{c}$ in the form of a cyt $\mathrm{c} / \mathrm{ZnO} \mathrm{NPs} / \mathrm{CPE}$ electrode was assessed by cyclic voltammetry. These nanoparticles helped cyt $\mathrm{c}$ to have a favored orientation and reduce the effective electron transfer distance. Present data describes that the designed biosensor can be useful in the bioelectrochemical and medical studies.

\section{References}

[1] M. T. Sulak, O. Gökdoğan, A. Gülce, and H. Gülce, "Amperometric glucose biosensor based on gold-deposited polyvinylferrocene film on Pt electrode," Biosensors and Bioelectronics, vol. 21, no. 9, pp. 1719-1726, 2006.

[2] S. Diré, F. Babonneau, C. Sanchez, and J. Livage, "Solgel synthesis of siloxane-oxide hybrid coatings $\left[\mathrm{Si}\left(\mathrm{CH}_{3}\right)_{2}\right.$ $\left.\mathrm{O} \cdot \mathrm{MO}_{x}: \mathrm{M}=\mathrm{SI}, \mathrm{Ti}, \mathrm{Zr}, \mathrm{Al}\right]$ with luminescent properties," Journal of Materials Chemistry, vol. 2, no. 2, pp. 239-244, 1992.

[3] H. Chen, X. Liu, H. Muthuraman et al., "Direct laser writing of microtunnels and reservoirs on nanocomposite materials," Advanced Materials, vol. 18, no. 21, pp. 2876-2879, 2006.

[4] S. S. Ozdemir, M. G. Buonomenna, and E. Drioli, "Catalytic polymeric membranes: preparation and application," Applied Catalysis A, vol. 307, no. 2, pp. 167-183, 2006.

[5] J. H. Park, Y. T. Lim, O. O. Park, J. K. Kim, J. W. Yu, and Y. C. Kim, "Polymer/gold nanoparticle nanocomposite lightemitting diodes: enhancement of electroluminescence stability and quantum efficiency of blue-light-emitting polymers," Chemistry of Materials, vol. 16, no. 4, pp. 688-692, 2004.

[6] K. S. Giesfeldt, R. M. Connatser, M. A. De Jesús, N. V. Lavrik, P. Dutta, and M. J. Sepaniak, "Studies of the optical properties of metal-pliable polymer composite materials," Applied Spectroscopy, vol. 57, no. 11, pp. 1346-1352, 2003.

[7] E. W. Kreutz, H. Frerichs, J. Stricker, and D. A. Wesner, Nuclear Instruments \& Methods in Physics Research Section B-Beam Interactions with Materials and Atoms, vol. 105, no. 1, 1995.

[8] I. Yoshinaga, N. Yamada, and S. Katayama, "Effect of inorganic components on thermal stability of methylsiloxane-based inorganic/orgnaic hybrids," Journal of Sol-Gel Science and Technology, vol. 35, no. 1, pp. 21-26, 2005.

[9] G. C. Yi, C. Wang, and W. I. Park, "ZnO nanorods: synthesis, characterization and applications," Semiconductor Science and Technology, vol. 20, no. 4, pp. S22-S34, 2005.

[10] Z. Qiuxiang, Y. Ke, B. Wei et al., "Synthesis, optical and field emission properties of three different $\mathrm{ZnO}$ nanostructures," Materials Letters, vol. 61, no. 18, pp. 3890-3892, 2007.

[11] L. Yuzhen, G. Lin, X. Huibin et al., "Low temperature synthesis and optical properties of small-diameter $\mathrm{ZnO}$ nanorods," Journal of Applied Physics, vol. 99, no. 11, Article ID 114302, 2006.

[12] A. Hachigo, H. Nakahata, K. Higaki, S. Fujii, and S. I. Shikata, "Heteroepitaxial growth of $\mathrm{ZnO}$ films on diamond (111) plane 
by magnetron sputtering," Applied Physics Letters, vol. 65, no. 20, pp. 2556-2558, 1994.

[13] H. Morkoç, S. Strite, G. B. Gao, M. E. Lin, B. Sverdlov, and M. Burns, "Large-band-gap SiC, III-V nitride, and II-VI ZnSebased semiconductor device technologies," Journal of Applied Physics, vol. 76, no. 3, pp. 1363-1398, 1994.

[14] W.-C. Shih and M.-S. Wu, "Growth of ZnO films on GaAs substrates with a $\mathrm{SiO}_{2}$ buffer layer by RF planar magnetron sputtering for surface acoustic wave applications," Journal of Crystal Growth, vol. 137, no. 3-4, pp. 319-325, 1994.

[15] M. H. Huang, S. Mao, H. Feick et al., "Room-temperature ultraviolet nanowire nanolasers," Science, vol. 292, no. 5523, pp. 1897-1899, 2001.

[16] N. T. Hung, N. D. Quang, and S. Bernik, "Electrical and microstructural characteristics of $\mathrm{ZnO}-\mathrm{Bi}_{2} \mathrm{O}_{3}$-based varistors doped with rare-earth oxides," Journal of Materials Research, vol. 16, no. 10, pp. 2817-2823, 2001.

[17] N. F. Cooray, K. Kushiya, A. Fujimaki et al., "Optimization of $\mathrm{Al}$-doped $\mathrm{ZnO}$ window layers for large-area $\mathrm{Cu}(\mathrm{InGa}) \mathrm{Se}_{2}$ based modules by RF/DC/DC multiple magnetron sputtering," Japanese Journal of Applied Physics, vol. 38, no. 11, pp. 6213-6218, 1999.

[18] R. Paneva and D. Gotchev, "Non-linear vibration behavior of thin multilayer diaphragms," Sensors and Actuators A, vol. 72, no. 1, pp. 79-87, 1999.

[19] E. Topoglidis, A. E. G. Cass, B. O’Regan, and J. R. Durrant, "Immobilisation and bioelectrochemistry of proteins on nanoporous $\mathrm{TiO}_{2}$ and $\mathrm{ZnO}$ films," Journal of Electroanalytical Chemistry, vol. 517, no. 1-2, pp. 20-27, 2001.

[20] L. Gao, Q. Li, W. Luan, H. Kawaoka, T. Sekino, and K. Niihara, "Preparation and electric properties ofdense nanocrystalline zinc oxide ceramics," Journal of the American Ceramic Society, vol. 85, no. 4, pp. 1016-1018, 2002.

[21] C. X. Xu and X. W. Sun, "Field emission from zinc oxide nanopins," Applied Physics Letters, vol. 83, no. 18, pp. 38063808, 2003.

[22] P. X. Gao, Y. Ding, W. Mai, W. L. Hughes, C. S. Lao, and Z. L. Wang, "Materials science: conversion of zinc oxide nanobelts into superlattice-structured nanohelices," Science, vol. 309, no. 5741, pp. 1700-1704, 2005.

[23] H. A.O. Hill, "The development of bioelectrochemistry," Coordination Chemistry Reviews, vol. 151, pp. 115-123, 1996.

[24] S. Song, R. A. Clark, E. F. Bowden, and M. J. Tarlov, "Characterization of cytochrome c/alkanethiolate structures prepared by self-assembly on gold," Journal of Physical Chemistry, vol. 97, no. 24, pp. 6564-6572, 1993.

[25] J. Yu and H. Ju, "Preparation of porous titania Sol-Gel matrix for immobilization of horseradish peroxidase by a vapor deposition method," Analytical Chemistry, vol. 74, no. 14, pp. 3579-3583, 2002.

[26] S. Rezaei-Zarchi, M. Negahdary, M. Doroudian et al., "Direct electron transfer of Myoglobin on nickel oxide Nanoparticles modified graphite electrode," Advances in Environmental Biology, vol. 5, no. 10, pp. 3241-3248, 2011.

[27] C. Nanjundiah, S. F. McDevitt, and V. R. Koch, "Differential capacitance measurements in solvent-free ionic liquids at $\mathrm{Hg}$ and C interfaces," Journal of the Electrochemical Society, vol. 144, no. 10, pp. 3392-3397, 1997.

[28] S. Mikoshiba, S. Murai, H. Sumino, and S. Hayase, "Another role of LiI/tert-butylpyridine in room-temperature molten salt electrolytes containing water for dye-sensitized solar cell," Chemistry Letters, no. 11, pp. 1156-1157, 2002.
[29] H. Fan, L. Yang, W. Hua et al., "Controlled synthesis of monodispersed $\mathrm{CuO}$ nanocrystals," Nanotechnology, vol. 15, no. 1, pp. 37-42, 2004.

[30] E. A. Meulenkamp, "Size dependence of the dissolution of $\mathrm{ZnO}$ nanoparticles," Journal of Physical Chemistry B, vol. 102, no. 40, pp. 7764-7769, 1998.

[31] A. J. Bard and L. R. Faulkner, "Electrochemical methods," in Fundamentals and Applications, p. 241, John Wiley \& Sons, New York, NY, USA, 2nd edition, 2001.

[32] E. Laviron, "General expression of the linear potential sweep voltammogram in the case of diffusionless electrochemical systems," Journal of Electroanalytical Chemistry, vol. 101, no. 1, pp. 19-28, 1979.

[33] E. Laviron, "The use of linear potential sweep voltammetry and of a.c. voltammetry for the study of the surface electrochemical reaction of strongly adsorbed systems and of redox modified electrodes," Journal of Electroanalytical Chemistry, vol. 100, pp. 263-270, 1979. 

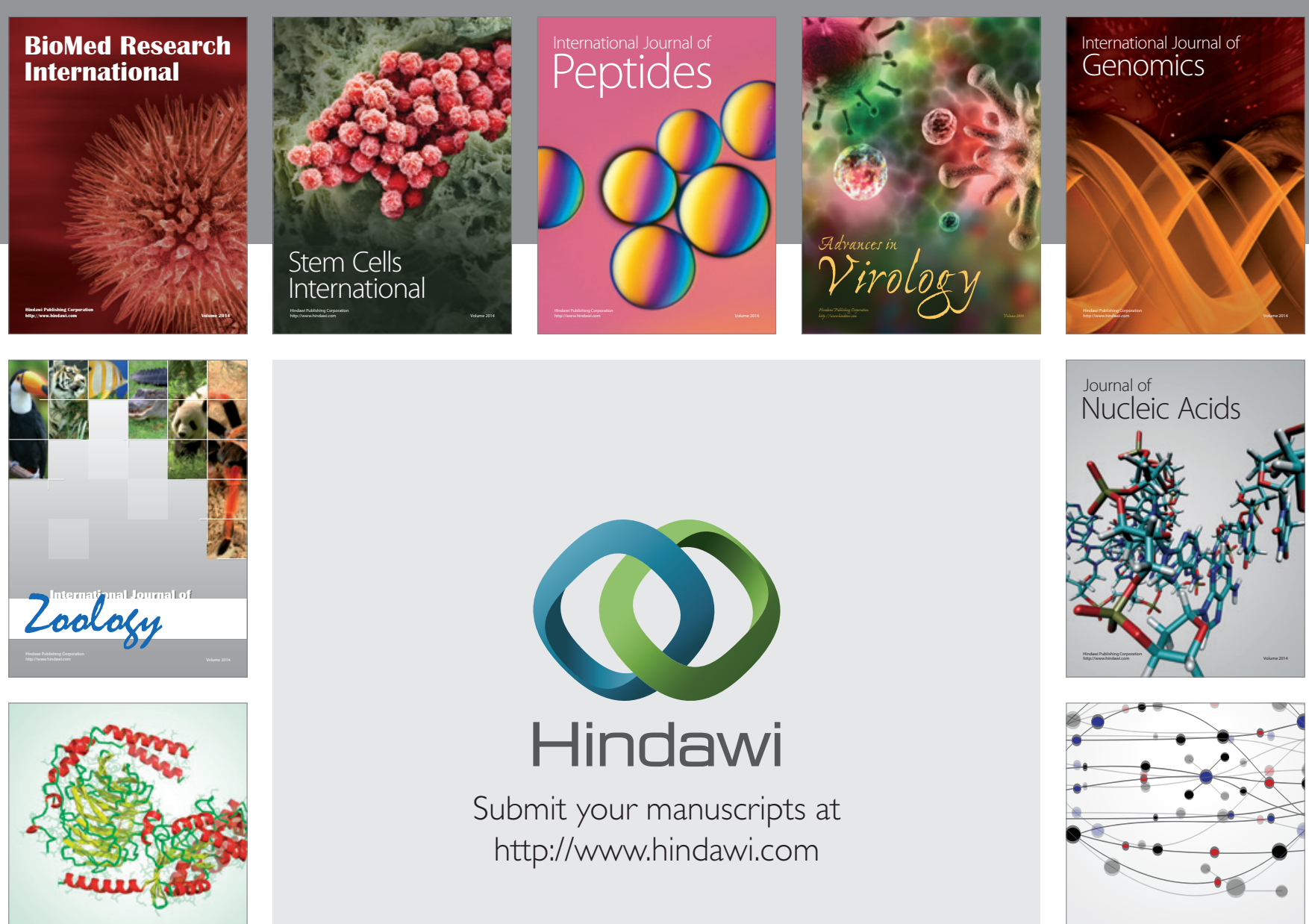

Submit your manuscripts at

http://www.hindawi.com

Signal ${ }^{\text {Jumal }}$ Transduction
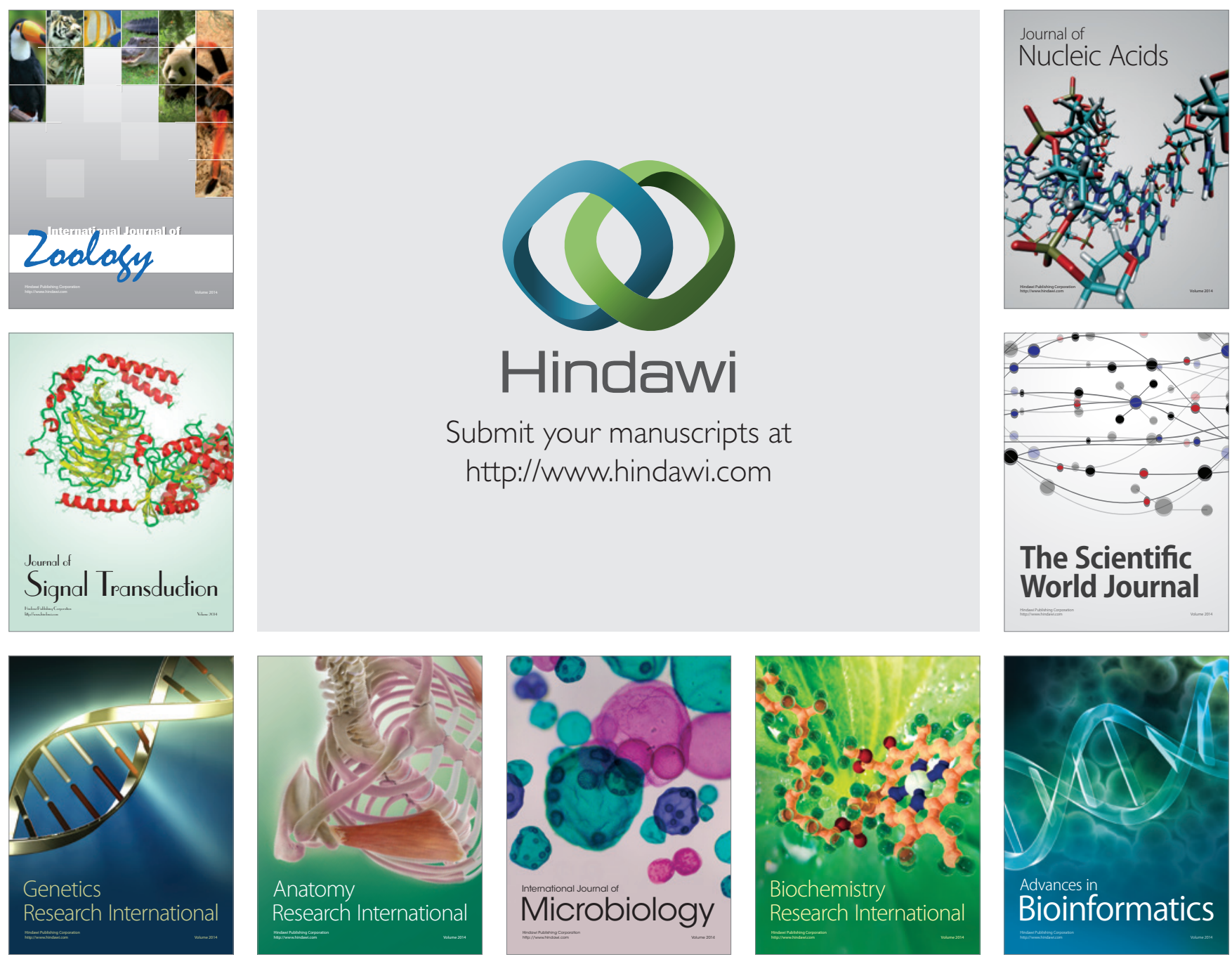

The Scientific World Journal
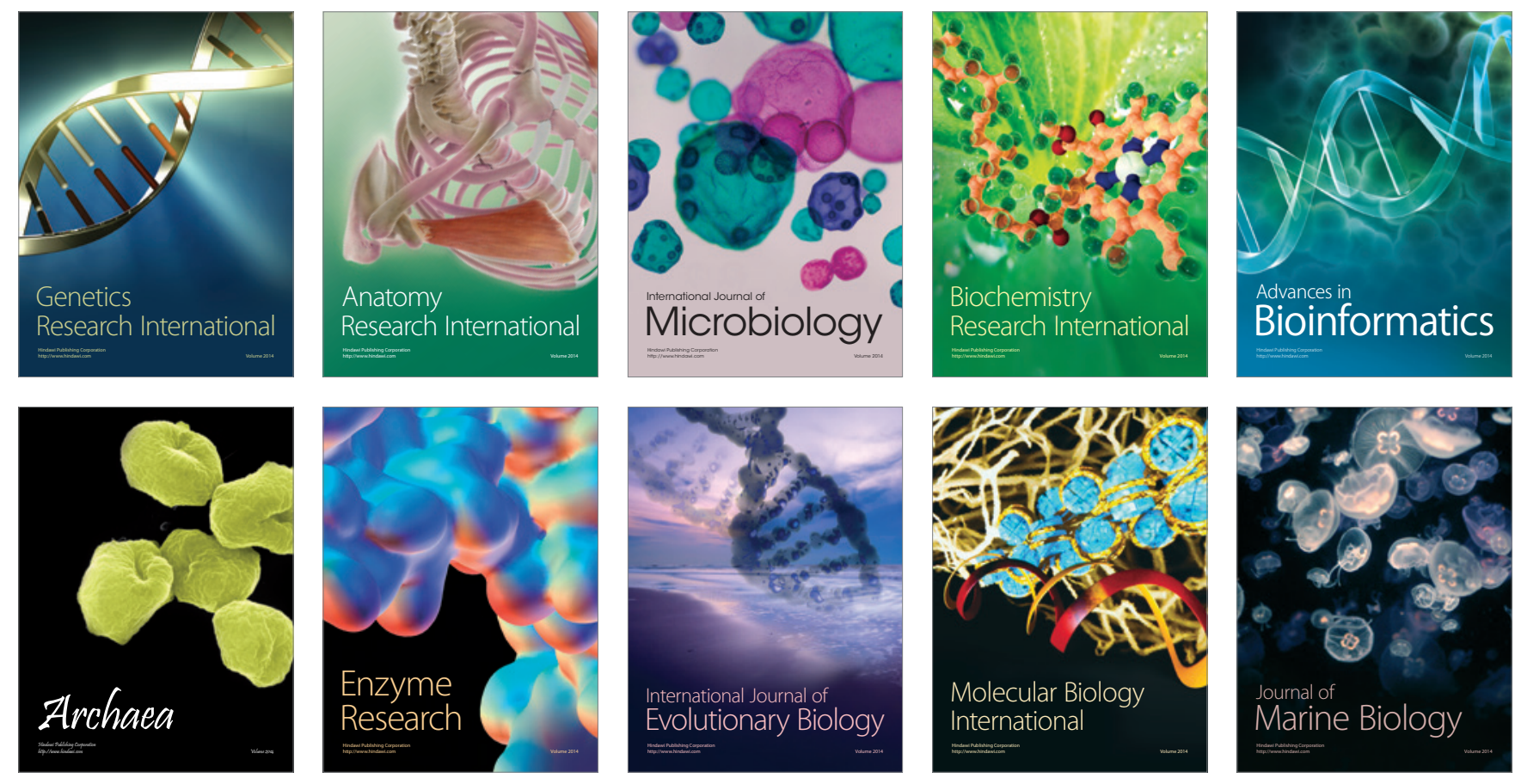